\title{
El canvi climàtic: canviar els valors abans que no sigui massa tard
}

\author{
Jordi Miralles, Fundació Terra \\ terra@terra.org
}

El control de les emissions de gasos amb efecte hivernacle com el diòxid de carboni és un dels principals objectius del protocol de Kyoto. L'important és entendre que és un problema greu i que cadascú pot ajudar a solucionar-lo.

Catalunya ha augmentat les emissions de gasos d'efecte hivernacle (diòxid de carboni $-\mathrm{CO}_{2}-\mathrm{i}$ similars).

A l'any base (mitjana 1990-1995), foren un total de $39.282 \mathrm{Gg}\left(1 \mathrm{Gg}=10^{9} \mathrm{~g}\right)$ de $\mathrm{CO}_{2}$ equivalent. L'any 2001 aquesta emissió fou de $52.270 \mathrm{Gg}$, un $33 \%$ superior. Les emissions de $\mathrm{CO}_{2}$ per càpita a Catalunya durant l'any 2001 han estat de 8,4 tones de $\mathrm{CO}_{2}$ per habitant i any, una xifra similar a la dels països rics.

El protocol de Kioto, un tractat internacional signat per l'Estat espanyol i vigent en el conjunt de la Unió Europea, estableix que cal reduir les emissions de gasos d'efecte hivernacle un $8 \%$ per al període 2008-2012 respecte del 1990. A l'estat espanyol li està permès incrementar les seves emissions en un $15 \%$, però en aquests darrers deu anys ha augmentat les emissions de gasos d'efecte hivernacle un $45 \%$.

És evident que no només no fem els deures per acomplir el compromís internacional del Protocol de Kioto; resulta que a casa nostra tenim la taxa més baixa d'eficiència energètica del conjunt de la Unió Europea.

Però aquesta realitat no és més que l'analítica que ens avisa que contribuïm perillosament a l'escalfament global del planeta.

\subsection{BONES RAONS CONTRA EL CANVI CLIMÀTIC}

El canvi climàtic és una realitat que ja no neguen els estaments científics. Informes de la Unió Europea assenyalen que per a l'horitzó 2025 el deteriorament ambiental pot ser catastròfic.
Si continua l'actual tendència, la població mundial passarà dels 6.400 milions actuals a 7.900 milions el 2025. Fins i tot polítics conservadors com Al Gore assenyalen que el canvi climàtic és el pitjor enemic de la Humanitat, per davant del terrorisme global.

El consum energètic dels nostres habitatges és responsable d'un $7 \%$ de les emissions a l'atmosfera. El consum energètic dels habitatges en els últims 30 anys ha augmentat un 40\%.

Només l'energia en il-luminació consumeix el $19 \%$ de la producció global d'energia elèctrica. Les bombetes incandescents inventades per Thomas Edison fa 120 anys que converteixen en llum només el $5 \%$ de l'energia que consumeixen. Representen el $80 \%$ de les bombetes tot i que tenim bombetes de baix consum que consumeixen quatre vegades menys per fer la mateixa quantitat de llum i duren prop de 10 vegades més; o les lluminàries de LED que poden dividir per 8 el consum en il-luminació i duren prop de 100 vegades més que les incandescents. Per altra banda el $28 \%$ dels gasos contaminants provenen dels nostres vehicles.

Des de 1990 el parc automobilístic a l'estat espanyol ha crescut un $45 \%$ i ja tenim una mitjana de 1,4 cotxes per habitant. Mentrestant cada any 16.000 espanyols moren per causes relacionades amb la mala qualitat de l'aire a les ciutats, 3 vegades més que les morts produïdes per accident de trànsit.

Estalviar energia no només repercuteix en un millor ambient sinó que també és més econòmic per a les nostres butxaques. Però també hi ha molts altres gestos que estalvien energia i són eficients: desplaçar-se en bicicleta en distàncies curtes, adquirir electrodomèstics eficients o instal-lar 
energies renovables a casa són algunes de les possibilitats a l'abast de tots, sense massa esforç. Però encara n'hi ha més.

El món que llegarem els nostres fills si continuen les tendències actuals no serà gens saludable. Perquè és evident que estimem els nostres, us proposem que amb ells compartim una imatge simpàtica. Al capdavall ser positius ens fa sentir bé i avui invertir en eficiència energètica, estalvi d'energia $i$ energies renovables és la millor fórmula per lluitar contra el canvi climàtic.

Tenim, doncs 10.000 raons per lluitar contra el canvi climàtic i cap per no fer-ho, perquè tots i cadascun de nosaltres podem fer que la nostra vida quotidiana sigui més respectuosa amb el medi ambient. Viure amb menys $\mathrm{CO}_{2}$ no és una experiència complicada i fins i tot pot ser plaent.

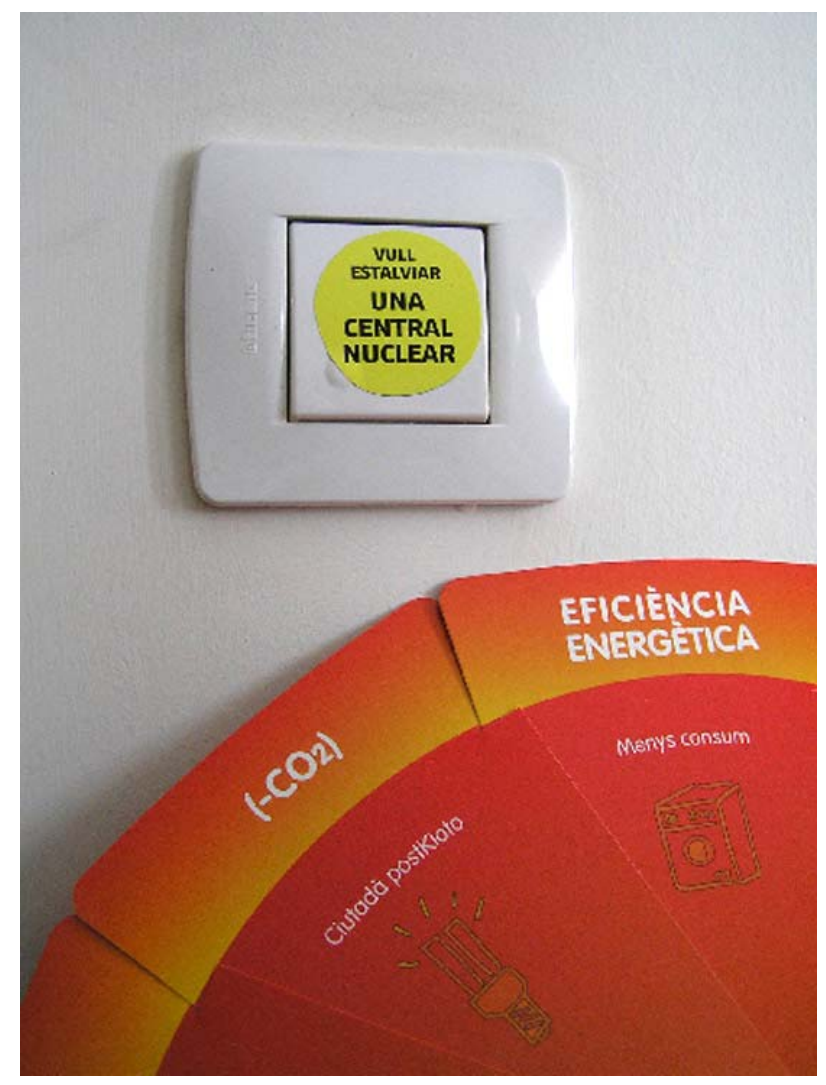

\section{Els principals impactes} del canvi climàtic

\section{Increment de la mortalitat}

Les morts anuals causades per l'escalfament global es doblaran en només 25 anys fins a apropar-se a les 300.000 persones: cops de calor, noves malalties, inundacions...

Les temperatures extremes ja estan afectant milers de persones. Els efectes de l'onada de calor de juliol i agost de l'any 2003 són prou coneguts. A França, per exemple, es van produir 11.435 morts més que en el mateix període de 2002 (tenint en compte l'estructura d'edat de la població).

Evitar l'augment d'al-lèrgies causada pel pol.len i les seves greus conseqüències per a la salut respiratòria. Les al-lèrgies no només són molestes, sinó que tenen una forta incidència en el mercat laboral. La pròpia contaminació atmosfèrica de les ciutats ja causa a l'estat espanyol uns 16.000 morts anuals, prop de 3 vegades més que els accidents de tràfic.

\section{Problemes psicosocials}

S'ha posat de manifest que els fenòmens meteorològics extrems tenen un impacte important sobre la salut mental de la comunitat afectada.

Després de les riuades que van tenir lloc a Polònia l'any 1997 es van registrar augments dels casos de suïcidis i d'alcoholisme, així com de desordres psicològics i de comportament, sobretot en nens.

Per últim, el canvi climàtic pot afectar l'economia, les infraestructures, l'oferta de recursos i, per tant, en certa forma, el moviment de la població.

Les sequeres dels darrers anys han provocat que la mitjana dels embassaments no hagi superat el $40 \%$ de la seva capacitat, generant problemes d'abastiment d'aigua en moltes poblacions. (Per altra banda recordem que una cinquena part de la Humanitat, uns 1.200 milions de persones no tenen accés a l'aigua potable!).

Durant l'onada de calor del 2003 molts països del sud de Europa van patir una caiguda de la producció agrària de fins el 30\%. El perill de desabastiment d'aliments és més real del que imaginem.

Fins a quin punt aquests problemes afectin a la salut dependrà de l'estatus econòmic i sociopolític que tenia la comunitat afectada abans de l'impacte, així com el de les comunitats veïnes. Alguns experts argumenten que, en qualsevol cas, seran els factors polítics derivats, no tant el canvi climàtic, els que tindran més influència sobre els problemes psicosocials.

\section{Augment del nivell del mar}

L'elevació del nivell del mar, tot i que incerta, tenint en compte que el $65 \%$ de la població mundial viu en zones del litoral, pot obligar milions de persones a l'abandonament de la seva llar original.

A Catalunya un increment de $5 \mathrm{~m}$ provocaria l'evacuació de 2,5 milions de persones.

Un estudi de l'Agència Europea del Medi Ambient argumenta que les temperatures augmenten. Al Ilarg del segle $X X$, la temperatura mitjana global del planeta s'ha incrementat $0,6^{\circ} \mathrm{C}$ i gairebé $1^{\circ} \mathrm{C}$ a Eu- 
ropa. Aquest escalfament està tenint efectes molt visibles, especialment sobre la fosa progressiva de les geleres de muntanya: nou de cada deu s'estan desfent. Seguint amb aquest ritme cap al 2050 el $75 \%$ de les geleres dels Alps hauran desaparegut. El mateix passa amb el gel Àrtic, que ha vist reduïda un $10 \%$ la seva superfície i un $40 \%$ el gruix del gel.

El 1996 l'aigua dolça fosa del gel de Groenlàndia era de $90 \mathrm{~km}^{3}$ però al 2005 ja era de $220 \mathrm{~km}^{3}$. Els efectes d'aquesta quantitat creixent d'aigua dolça en els oceans podria tenir conseqüències catastròfiques, no només per l'increment del nivell del mar sinó pels seus efectes sobre el corrent del Golf.

En el darrer segle l'augment del nivell del mar ha estat d'entre 10 i $25 \mathrm{~cm}$, però podria augmentar fins a $88 \mathrm{~cm}$ per a l'any 2100 . Si tenim en compte la gran quantitat de persones que viuen al litoral això podria posar en perill la supervivència de 70 milions d'habitants que viuen a la costa. Tampoc podem oblidar que aquesta desfeta dels gels suposa una amenaça per a moltes de les espècies àrtiques $i$ antàrtiques, com ara l'ós polar, les foques i morses i els pingüins.

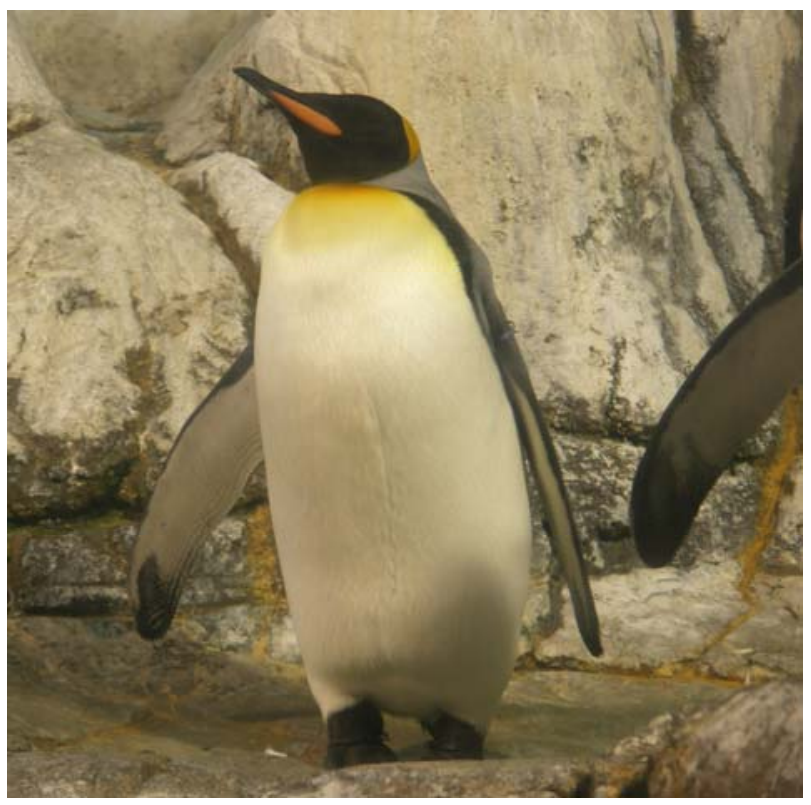

Nous valors per fer front al canvi climàtic

No creiem que calgui alliçonar ningú, perquè cadascun de nosaltres, amb el nostre estil de vida, som el millor exemple del que no fem bé.

Un món on el $20 \%$ de la Humanitat consumeix el $80 \%$ dels recursos, és evident que no és just ni saludable. Un món que consumeix l'equivalent a la capacitat bioproductiva de 4 planetes, només ho pot fer consumint els recursos de les generacions futures.

Finalment, ara comencem a entreveure els efectes d'aquesta orgia planetària que uns 1.000 milions d'humans portem des de fa al voltant d'un segle. Ha arribat l'hora de posar-hi seny i per això el conjunt de la societat ha de posar fre al consumisme 0 al model socioeconòmic capitalista que basa el seu funcionament en el creixement continuat. Aquest creixement ja està clar que no és factible.

Alguns economistes com Nicholas GeorgescuRoegen plantegen que hem de decréixer si volem fer front al futur. Altres experts assenyalen que l'economia només pot sobreviure si deixa el consumisme i es fonamenta en el serveis. Les persones no necessitem "rentadores", el que necessitem és "rentar" la roba. El leasing de bens i serveis és l'únic sistema per continuar innovant i progressant i reduir la demanda de recursos naturals.

Però sobretot, també cal reduir l'actual creixement poblacional. Les dades que aporten els ecòlegs experts en l'indicador de la petjada ecològica (footprint) no deixen lloc a dubte que incrementar la població vol dir reduir el nombre d'hectàrees bioproductives del planeta $\mathrm{i}$, per tant, o començar a malviure o extreure recursos del futur. La mitjana de la nostra petjada ecològica és de 4 hectàrees per habitant $i$ any mentre que la mitjana mundial no arriba a 2 mentre que la dels Estats Units és de 9!

La nostra travessia com a civilització embarcada en un Titànic ple de luxe i ben engreixat ha albirat el seu particular iceberg quan anem a tota potència.

Ara mateix, el problema no és només que aturem els motors sinó que reinvertim la marxa. Amb els motors ja reinvertits, tot i així, mentre el vaixell llisca per la inèrcia no ens hem de quedar amb els braços plegats. Disposem de la tecnologia per viure de forma molt més eficient. Disposem del coneixement per fabricar productes reciclables i que puguin ser fàcilment reparables i no esdevinguin residus perillosos. Disposem d'energies renovables per viure amb auster confort...

Ens cal fer realitat un nou estil de vida basat precisament en la simplicitat i l'austeritat; en el compartir i en la solidaritat.

Mentrestant podem assajar un bon nombre de comportaments que poden estalviar, per si sols, el $50 \%$ de l'energia que consumim a casa nostra.

Lògicament ens queda molt per fer com a societat, però el primer pas l'hem de donar a casa, perquè serveixi de motivació a la nostra mainada. El darrer pas és educar en nous valors basats en una ètica socioambiental. 
Amb altres paraules: o assumim que som part de la natura o no serem. L'actual egocentrisme ens ha portat ja a les envistes del canvi climàtic. No tenim certesa de com s'expressarà, però sí que sabem que l'increment de $\mathrm{CO}_{2}$ va correlacionat $\mathrm{amb}$ l'augment de la temperatura, tal com ho avalen les mesures dels darrers 600.000 anys (anàlisi de l'aire capturat en els gels antàrtics). I que això pot comportar canvis que portin molt de patiment a la nostra espècie i als ecosistemes en general.

Tampoc podem oblidar que la nostra civilització és l'aportació de cadascun de nosaltres. És per això que els petits canvis són poderosos, encara que els grups de poder afirmin que no tenim res a fer...

\section{Els gestos ambientals que podem fer}

La Fundació Terra ha posat en marxa un tapís digital al web www.josoclasolucio.com (fig. 1) que pretén recollir en imatges fotogràfiques (fig. 2) gestos ciutadans contra el canvi climàtic.
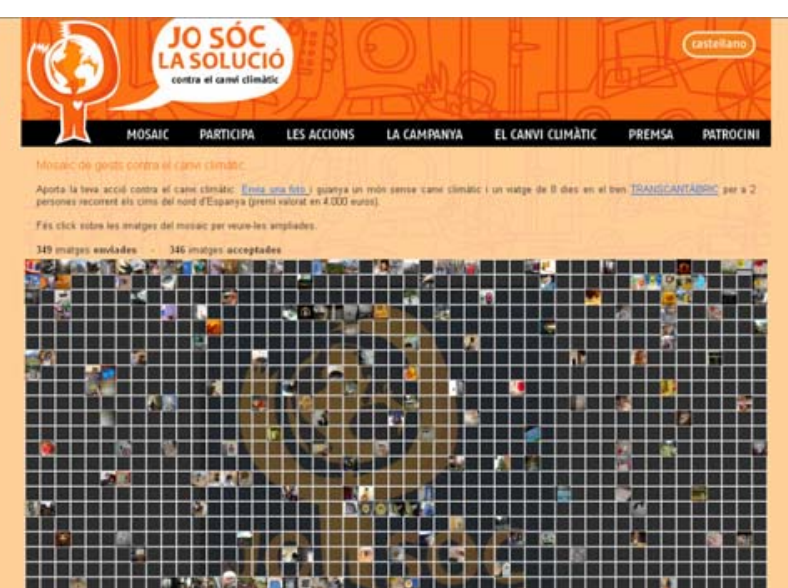

Figura 1. Pàgina d'inici del web "jo sóc la solució”.

L'objectiu d'aquest tapís d'imatges (hi ha espai per a 10.000 imatges) és compartir la inquietud creixent i no quedar-nos amb els braços plegats. En el marc d'aquesta campanya, la Fundació Terra proposa vuit coses senzilles o gestos que tots podem fer; la suma dels quals pot comportar un estalvi de fins el $50 \%$ d'energia en un habitatge.

Està clar, tanmateix, que hi ha altres comportaments com ara invertir en energies renovables, estalviar aigua, viatjar menys o no sobrepassar els 90 $\mathrm{km} / \mathrm{h}$ anant en cotxe. Els gestos concrets que es promouen amb aquesta campanya són:

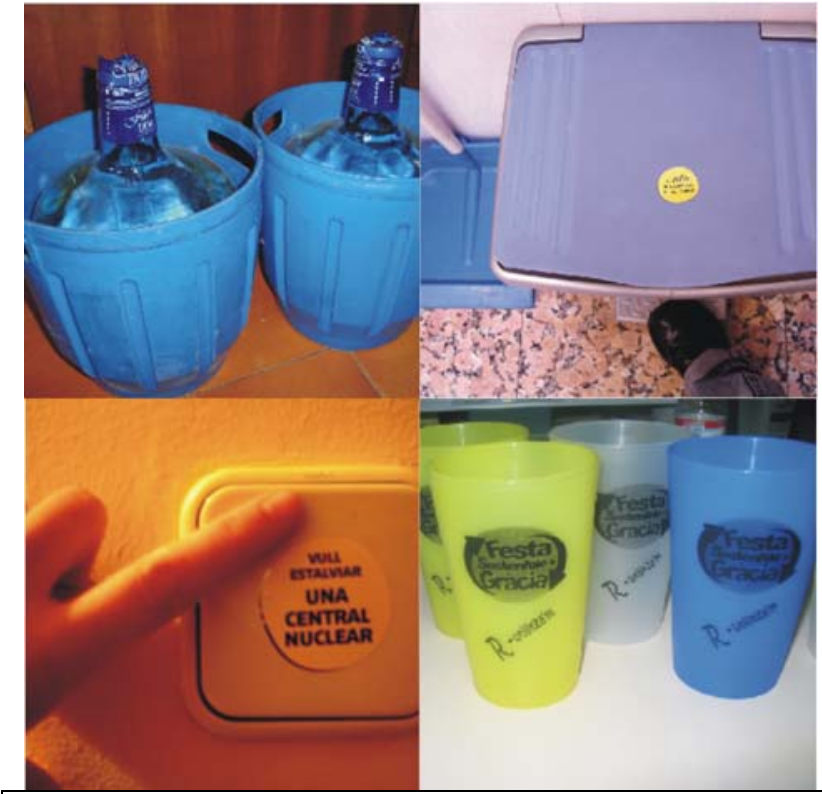

Figura 2. Algunes de les imatges penjades a la web "jo sóc la solució". D'esquerra a dreta i de dalt a baix: a) Envàs reutilitzable. b) Reciclatge. c) Apagar llums. d) Qui vulgui muntar festes sostenibles a Gràcia que demani gots reutilitzables.

1) II-Iuminació de baix consum. Substituir bombetes incandescents i halògenes per bombetes fluorescents compactes o de LEDS

2) Aparells energèticament eficients. Adquirir aparells elèctrics que no malversin energia, com els anomenats energèticament de Classe $A, A+$, $A++o$ que acompleixin altres criteris d'estalvi com Energy Star, etc.

3) Tria i selecció de la brossa de casa. Recollir selectivament les escombraries i portar les fraccions com ara paper, envasos o matèria orgànica al contenidor corresponent i la resta de valoritzables a la deixalleria estalvia energia i contaminació.

4) Climatització de baix consum. Seleccionar el termòstat de la climatització a l'estiu a $26^{\circ} \mathrm{C}$ i a I'hivern a $20^{\circ} \mathrm{C}$ i utilitzar aparells de baix consum com ara les bombes de calor tipus inverter.

5) Moure's en bicicleta o transports col-lectius. Per a recorreguts de menys de $3 \mathrm{~km}$ la bicicleta és el sistema de locomoció més eficient. Els transports collectius redueixen a una quarta part les emissions de gasos amb efecte hivernacle.

6) Conduir eficientment. Canviar de marxa per sota de les 2.500 revolucions en els vehicles de gasolina i per sota de les 2.000 en els de gasoil pot estalviar un $35 \%$ de combustible.

7) Consum local. Avui el $40 \%$ de les emissions són per causa del transport de mercaderies per tot el món. Cada vegada que comprem al barri o 
adquirim articles produïts localment (fruita de comarques veïnes en comptes d'altres països, carn d'aquí en comptes d'Irlanda o Argentina) estalviem en emissions d'efecte hivernacle.

8) Habitatges aïllats. Finestres i portes poden aportar pèrdues importants de climatització si no estan ben aïllades. El doble vidre a les finestres i l'aïllament a les caixes de les persianes poden reduir la factura energètica.

Ben segur que el món escolar podria animar als nois i noies a retratar les coses que ja es fan ben fetes o amb les quals ens apliquem per reduir la despesa energètica i de recursos naturals.

Una imatge escaient de vegades val més que mil paraules. És només una idea per no oblidar que tots nosaltres som la solució.

\section{RECURSOS}

\section{PER CONSULTAR I LLEGIR}

\section{Llibres}

Bourseiller, Philippe. 365 gestos para salvar el planeta. Lunwerg Editores. Barcelona, 2005.

Braungart, Michael \& McDonough, William. Cradle to cradle. De la cuna a la cuna. Editorial McGraw-Hill. Madrid, 2005

Brown, Lester. Salvar el mundo. Plan B: Ecología para un mundo en peligro. Editorial Paidós. Barcelona, 2004.
Diamond, Jared. Colapso. Editorial Random House Mondadori - Debate. Barcelona, 2006

Gore, Al. An inconvenient truth. Rodale Publisher. New York, 2006. (Llibre que recull les dades que serviren per al film "Una verdad incómoda").

Merkel, Jim. Simplicidad Radical. Fundació Terra. Barcelona, 2005.

Roddick, Anita. Tómatelo como algo personal. Cómo té afecta la globalización y vías eficaces para afrontarla. Icaria editorial - Intermón Oxfam. Barcelona, 2005.

Scheer, Herman, Economía solar. Estrategias para la modernidad ecológica. Círculo de LectoresGalaxia Guttemberg. Barcelona, 2002.

\section{Webs}

Informe del canvi climàtic a Catalunya: http://www.iecat.net/CanviClimatic/Informe menu.htm

Web del film "Una verdad incómoda": http://www.climatecrisis.org

Web de la Direcció General d'energia de la Comissió Europea amb el pla de reducció d'emissions i la campanya contra el canvi climàtic: http://ec.europa.eu/energy/energy policy/index en.htm 